\title{
Insulin-Related Lipohypertrophy: Lipogenic Action or Tissue Trauma?
}

\section{OPEN ACCESS}

Edited by:

Andrea Enzo Scaramuzza,

Istituti Ospitalieri di Cremona, Italy

Reviewed by:

Stefano Zucchini,

Policlinico S. Orsola Malpighi, Italy

Gianfranco Meloni,

University of Sassari, Italy

*Correspondence:

Anil Bhansali

anilbhansaliendocrine@gmail.com

Specialty section:

This article was submitted to

Pediatric Endocrinology,

a section of the journal

Frontiers in Endocrinology

Received: 30 January 2018 Accepted: 08 October 2018

Published: 30 October 2018

Citation:

Barola A, Tiwari P, Bhansali A,

Grover S and Dayal D (2018)

Insulin-Related Lipohypertrophy:

Lipogenic Action or Tissue Trauma?

Front. Endocrinol. 9:638.

doi: 10.3389/fendo.2018.00638

\begin{abstract}
Anjana Barola ${ }^{1}$, Pramil Tiwari ${ }^{1}$, Anil Bhansali ${ }^{2 *}$, Sandeep Grover ${ }^{3}$ and Devi Dayal ${ }^{4}$
${ }^{1}$ Department of Pharmacy Practice, National Institute of Pharmaceutical Education and Research, Mohali, India, ${ }^{2}$ Department of Endocrinology, Postgraduate Institute of Medical Education and Research, Chandigarh, India, ${ }^{3}$ Department of Psychiatry, Postgraduate Institute of Medical Education and Research, Chandigarh, India, ${ }^{4}$ Department of Paediatrics, Postgraduate Institute of Medical Education and Research, Chandigarh, India
\end{abstract}

Lipohypertrophy has been suggested as an outcome of lipogenic action of insulin and/or injection-related tissue trauma. In a cross-sectional study, we evaluated the predictors of lipohypertrophy in 372 type 1 diabetes patients (mean age 17.1 years) receiving subcutaneous insulin with pen and/or syringes for $\geq 3$ months. On examining injection sites with inspection and palpation technique, 62.1\% patients demonstrated lipohypertrophy. Univariate analysis showed that gender, BMl, HbA1c, injection device, rotation, injection area, needle length, insulin regimen, and total daily dose of insulin were associated with lipohypertrophy $(p<0.05)$. Notably, the mean needle reuse was comparable in patients with or without lipohypertrophy (8.1 vs. $7.2, p=0.534)$. In multivariate logistic regression, gender, $\mathrm{HbA1c}$, TDD, injection devices, and needle length lost its significance. Further, injections over smaller area $(\leq 8.5 \times 5.5 \mathrm{~cm})$ and non-rotation of sites were found to be strongest independent predictor of lipohypertrophy $(p<0.0005$ for both) with increased odds of 23.2 (95\% Cl 9.1-59.2) and 6.3 (95\% Cl 3.4-11.9) times, respectively. Being underweight was also a significant independent predictor (odds ratio [OR] 13.0 [95\% Cl 2.2-75.2], $p=0.004$ ). Compared to rapid plus long-acting analogs, regular insulin plus long-acting analogs and conventional premixed insulin users had $3.2(95 \% \mathrm{Cl} 1.5-6.8, p=0.003)$ and $4.6(95 \% \mathrm{Cl} 1.4-15.7, p=0.014)$ fold higher risk of lipohypertrophy (mean injection frequency 4.01 vs. 4.01 vs. 2.09, respectively). Sub-group analysis showed that lipohypertrophy was $79 \%$ less likely in patients with multiple daily injections $(\geq 4)$ than twice-daily regimen (OR 0.21, $p<0.0005)$. Moreover, lipohypertrophy was reduced to half with bolus doses of rapid-acting insulin analogs than regular insulin $(p=0.003)$, even though mean injection frequency was comparable (4.01 vs. 3.93, $p=0.229$ ). This difference was statistically insignificant for basal doses with $\mathrm{NPH}$ or long-acting analogs $(p=0.069)$. Therefore, injection area, rotation, BMI, and insulin regimen are the best predictors of lipohypertrophy and together could correctly identify lipohypertrophy status in $84.4 \%$ patients with excellent discrimination capability (AUC $=0.906, p<0.0005$ ). In conclusion, findings of our study suggest that delivering rapidly absorbed insulin analogs over large injection area along with greater split of total daily doses reduce insulin-induced lipogenesis and outplay tissue trauma added through frequent injections and needle reuse.

Keywords: lipohypertrophy, type 1 diabetes, lipogenic action, tissue trauma, needle reuse, insulin analogs, insulin regimen, injection frequency 


\section{INTRODUCTION}

At present, the daily exogenous insulin replacement for the lifetime is the only available therapeutic option to manage majority of patients with type 1 diabetes mellitus (T1DM) (1). Repeated subcutaneous administration of insulin in the smaller area mount up the local lipogenic effect of insulin and injectionrelated tissue trauma, consequently, ensues lipohypertrophy in form of fatty lumps underneath the skin of that area (2). These lipohypertrophic swellings are not only unsightly but also may result into marked variability in insulin absorption, subsequently causing glycaemic excursions (3). A recent metaanalysis involving 26 studies has estimated $38 \%$ of overall pooled prevalence of lipohypertrophy in insulin-treated patients (4). Thus, mapping the predictors of lipohypertrophy is imperative to minimize this highly prevalent unwanted effect of insulin therapy.

Many researchers have examined the association of lipohypertrophy with age, gender, duration of therapy, body mass index, glycated hemoglobin, total daily dose of insulin (TDD), type of insulin, injection frequency, needle reuse, injection sites, and missing rotations (5-7). These observations have made important contributions to the current knowledge; however, there is a need of more studies because of numerous reasons. First, data regarding predictors of lipohypertrophy in T1DM were largely available from the limited studies $(2,8-12)$. Second, the relatively smaller sample sizes of these studies might have reduced their power to identify significant associations. Third, several researchers only employed univariate analysis, hence were unable to account the effect of other explanatory variables and confounders on the lipohypertrophy $(8,9)$. Fourth, some of these studies classified lipoatrophy as grade-3 lipohypertrophy (10), thereby invalidating the parameter estimates of lipohypertrophy. Lastly, after the introduction of newer insulin analogs, only one study involving T1DM patients examined the association of lipohypertrophy with type of insulin (12). Lipohypertrophy, being a primary outcome of lipogenic action of insulin, warrants systematic examination of its association with commonly used insulin classes and their administration frequencies. It is of particular interest, as multiple daily injections (basal-bolus regimens) have become the standard of care with introduction of newer insulin analogs.

Thus, present study aimed to examine the predictors of lipohypertrophy with particular emphasis on insulin regimens and types of insulin in a large sample of type 1 diabetes patients with appropriate statistical analysis.

\section{MATERIALS AND METHODS}

\section{Participants}

This cross-sectional questionnaire based study was conducted at Post Graduate Institute of Medical Education and Research (PGIMER) Chandigarh, India. A consecutive sample of 372 type 1 diabetes patients was recruited who agreed to participate in the study. The inclusion criteria were: (1) patients with history of diabetic ketoacidosis (DKA) and/or treated with insulin since diagnosis complemented with GAD-65 positivity and (2) at least 3 months of insulin administration with pen devices or syringes or combination of both. Exclusion criteria were (1) patients in partial remission (honeymoon phase) as identified by insulin dose-adjusted HbA1c (IDAA1c) < 9 (13); (2) patients prescribed with insulin regimens other than rapid-acting analogs plus long-acting analogs, regular insulin plus long-acting analogs, regular insulin plus Neutral Protamine Hagedorn (NPH) and conventional premixed insulins; and (3) patients with pregnancy.

Questionnaire was prepared by referring the relevant literature and consulting the experts. Patients who selfadministered insulin were interviewed face to face; otherwise, responses were taken from the injection performing caregiver in the presence of the patient. All the participants were explained about the study protocol. In case of patients below the age of 18 years, we obtained written assent along with written parental or adult caregiver informed consent. For all the patients above the age of 18 years, a written informed consent was obtained. The study was conducted in accordance with the Declaration of Helsinki and approved by the PGIMER Institutional Ethics Committee.

\section{Parameters and Procedures}

Demographic information and current injection practice patterns were captured. The recorded parameters were age, gender, duration of diabetes, monthly family income, qualification and occupation of head of family, height and weight of the patient, injection administrator(s), glycated hemoglobin, type of injection device(s), needle length, extent of needle or syringe reuse, injections frequency and types of insulin (insulin regimen), total daily dose of insulin (TDD), injection site(s), injection area size measured within one side of site (for example, left or right side of the abdomen), rotation within injecting zone, and presence, type and location of lipodystrophy.

Real time update of Kuppuswamy socioeconomic status scale was used to measure the socioeconomic status of the patient. It is based on the composite score obtained from the occupation and qualification category of head of the family and monthly family income $(14,15)$. Principle earner of the family was considered as head of the family.

For adults, WHO recommended BMI cut-off points for Asians were used to categorize underweight $\left(<18.5 \mathrm{~kg} / \mathrm{m}^{2}\right)$, normal $\left(18.5-23 \mathrm{~kg} / \mathrm{m}^{2}\right)$, overweight $\left(23.0-27.5 \mathrm{~kg} / \mathrm{m}^{2}\right)$ and obese $>27.5$ $\left.\mathrm{kg} / \mathrm{m}^{2}\right)(16)$. For children between 5 and 18 years, revised Indian Academy of Pediatrics (IAP) growth charts were used to define overweight and obese category as adult equivalent of 23 and 27.5 cut-offs (17).

Glycated hemoglobin (HbAlc) values measured within past 2 weeks were documented. Needle use frequency was calculated by questioning "on an average how many insulin injections were administered with the single needle/syringe." Size of needles and syringes was evaluated either based on self-report or looking into medical inventories. Insulin regimen, types of insulin, and total daily dose of insulin were noted from the medical records.

Size of the injecting zone was assessed using the standard size credit card $(8.56 \times 5.39 \mathrm{~cm})(18)$, playing card $(8.89 \times 6.35 \mathrm{~cm})$ and Indian postal card $(14 \times 9 \mathrm{~cm})(19)$. Patients were shown these cards to recognize the size of their injecting area. Correct 
site rotation was defined as injections within any half or quadrant with spacing of at least $1 \mathrm{~cm}$ for the subsequent injection and then moving to next half or quadrant in the following week (20).

Presence of lipodystrophy at injection sites was ascertained with inspection and palpation techniques. Visible or palpable lump was indicative of lipohypertrophy, while depression at the injection site was suggestive of lipoatrophy (21). Lipohypertrophy was further confirmed with pinch maneuverer showing non-symmetric bilateral skin folds (22). Interviewer was not aware about the prior status of lipodystrophy because injection sites were checked only after the collection of all other data.

\section{Sample Size Calculation}

We performed sample size calculations with Pocock's formula (n $\left.=\mathrm{Z}^{2} \mathrm{P}(1-\mathrm{P}) / \mathrm{d}^{2}\right)$ using lipohypertrophy prevalence estimates of $41 \%$ from a previous study conducted in the same center (23). It predicted that 372 patients were needed to achieve $5 \%$ precision and $95 \%$ confidence interval.

\section{Statistical Analysis}

Predictors of lipohypertrophy were identified by examining data in sequential steps with SPSS version 20 . The $P$-value $<0.05$ was considered as statistically significant.

In the first step, initial selection of variables explaining lipohypertrophy was done. Significant continuous and categorical variables were recognized with Mann-Whitney $U$ test and Pearson chi-square test, respectively. Contingency tables showed that none of the categorical variables had a low expected count ( $<5$ for $20 \%$ of cells) which ensured the suitability of Pearson chi-square test. In the second step, unadjusted odds ratio of each variable found to be significant in the first step were estimated with univariate binary logistic regression. In last step, we performed stepwise multivariate logistic regression analysis using backward selection approach and started with full model comprising all significant variables shortlisted in first step. Then we kept removing one insignificant variable at a time, until all the remaining variables stayed statistically significant that indicated the final model. Adjusted odds ratios estimated in the re-fitted final model were reported. Hosmer-Lemeshow goodness of fit test (HLGOF) and ROC analysis of the final model assessed its calibration and discrimination ability, respectively.

\section{RESULTS}

Of 372 patients enrolled in the study, $54.8 \%$ were males. The average age of patients was 17.1 years (range $5.0-50.6$ years) with 5.6 years of mean duration of diabetes (range $0.3-36.7$ years).

Insulin was administered with pen devices in $73.7 \%$ patients and by syringes in $20.2 \%$. Remaining patients used combination of both (for example, bolus insulin with syringe and basal with pen or vice versa). The patients themselves administered insulin injections in $62.6 \%$ cases followed by patient-caregiver dyads $(20.4 \%)$ and caregivers (16.9\%). Basal-bolus therapy was prescribed to $87.4 \%(n=325)$ patients. Of these, $62.2 \%(202 / 325)$ took rapid-acting insulin analogs and $37.8 \%$ (123/325) regular insulin for bolus doses. For the basal doses, long-acting insulin analogs were used in 91.4\% (297/325) patients and NPH in $8.6 \%(28 / 325)$. Conventional premixed insulin regimen (2 to 3 injections) was recommended to $12.6 \%(n=47)$ patients.

In the present study, lipodystrophy was observed in $62.6 \%$ of patients $(n=233)$. Of 372 patients, 229 exhibited lipohypertrophy, two lipoatrophy and two experienced both. Therefore, the total prevalence of lipohypertrophy was $62.1 \%$ $(n=231)$ and of lipoatrophy was $1.1 \%(n=4)$. Total events were 379 as some patients developed lipohypertrophy at more than one site. With regard to the specific injection site, highest proportion of lipohypertrophic lumps were found at abdomen $(200 / 316,63.3 \%)$, followed by thigh $(81 / 131,61.8 \%)$ upper arm $(85 / 138,61.6 \%)$ and buttocks $(5 / 10,50.0 \%)$. Eight patients had lipohypertrophy at irrational sites (calf and forearm). When asked about injecting into lipodystrophic lesions, $60.8 \%$ patients indicated that they continued injecting into these areas.

Univariate analysis showed that age, duration of diabetes, socioeconomic status, injection administrator, needle reuse, TDD/kg body weight, and number of injection sites were not associated with lipohypertrophy $(p>0.05)$. Notably, the mean needle reuse was comparable in patients with or without lipohypertrophy (8.1 vs. $7.2, p=0.534)$. Statistically significant association $(p<0.05)$ was attained between the lipohypertrophy and nine variables [gender, $\mathrm{HbA} 1 c$, TDD, BMI, insulin delivery device, needle length, insulin regimen (injection frequency), injection area size, and injection rotation] (Tables 1, 2).

At first, we included all nine significant variables in the multivariate logistic regression. This model was statistically significant $\left[\chi_{(17)}^{2}=234.730, p<0.0005\right]$, explained $63.7 \%$ of the variance in the lipohypertrophy (Nagelkerke $\mathrm{R}^{2}$ ) and correctly classified $85.8 \%$ of cases. In this model, HbAlc, gender, TDD, injection device, and needle length lost their significance after adjusting for other variables. Next, we eliminated most insignificant variable one at a time starting from HbAlc (0.938), gender $(p=0.326)$, TDD $(p=0.224)$, injection device $(p=$ $0.200)$, and needle length $(p=0.096)$ in a sequential manner. Even then, they remained insignificant in subsequent models and henceforth were dropped.

Lastly, multivariate logistic regression was performed to ascertain the effects of BMI, injection area size, injection rotation and insulin regimen (injection frequency) on the likelihood of lipohypertrophy. This re-fitted logistic model was statistically significant $\left[\chi_{(9)}^{2}=222.171, p<0.0005\right]$, well-calibrated (HLGOF $p=0.410$ ) and had excellent discrimination quality (AUC $=$ 0.906, $p<0.0005)$. All four variables remained statistically significant indicating the retention of this model as final. Correct case classification (84.4\%) and explained variance were negligibly reduced (61.2\%) when compared with starting model. Thus, elimination of the five variables viz. HbA1c, gender, TDD, injection device, and needle length from this final model did not affect its predictability.

Adjusted odds ratio estimated from the final model revealed that underweight patients had 13-folds increased odds for developing lipohypertrophy than the obese $(p=0.004)$. Further, patients injecting in area equivalent to credit card size were at 
TABLE 1 | Quantitative independent variables grouped based on lipohypertrophy status and the significance of observed differences.

\begin{tabular}{|c|c|c|c|c|}
\hline Variables & $\begin{array}{c}\text { Total } \\
n=372 \\
\text { Mean } \pm \text { SD }\end{array}$ & $\begin{array}{l}\text { Lipohypertrophy } \\
\text { present }(n=231) \\
\text { Mean } \pm \text { SD }\end{array}$ & $\begin{array}{l}\text { Lipohypertrophy } \\
\text { absent }(n=141) \\
\text { Mean } \pm \text { SD }\end{array}$ & $\begin{array}{c}\text { Significance } \\
\text { (Mann-Whitney U } \\
\text { test) }\end{array}$ \\
\hline Age (years) & $17.1 \pm 7.4$ & $17.1 \pm 7.8$ & $17.2 \pm 6.7$ & 0.441 \\
\hline Duration of diabetes (years) & $5.6 \pm 5.3$ & $5.7 \pm 5.5$ & $5.4 \pm 5.1$ & 0.381 \\
\hline $\mathrm{HbA1c}(\%)$ & $9.7 \pm 2.6$ & $10.0 \pm 2.7$ & $9.2 \pm 2.4$ & $0.007^{a}$ \\
\hline Frequency of needle reuse & $7.8 \pm 8.0$ & $8.1 \pm 8.9$ & $7.2 \pm 6.1$ & 0.534 \\
\hline Total daily dose (TDD) of insulin (units) & $40.7 \pm 18.1$ & $38.3 \pm 16.9$ & $44.8 \pm 19.2$ & $0.001^{a}$ \\
\hline TDD of insulin per kg bodyweight (units/kg) & $0.97 \pm 0.37$ & $0.95 \pm 0.37$ & $0.99 \pm 0.38$ & 0.402 \\
\hline Insulin dose adjusted HbA1c & $13.5 \pm 3.0$ & $13.7 \pm 3.1$ & $13.2 \pm 2.8$ & 0.097 \\
\hline
\end{tabular}

a Statistically significant.

23.2 times higher risk for lipohypertrophy than post card size area users $(p<0.0005)$. Patients not performing injection rotation exhibited 6.3-folds more likelihood of lipohypertrophy than those adhering to rotation $(p<0.0005)$. Furthermore, regular insulin plus long-acting analogs users had 3.2 increased odds of developing lipohypertrophy than rapid plus long-acting analogs users $(p=0.003)$ with equivalent mean injection frequency (4.01 for both). Interestingly, patients treated with conventional premixed insulins had 4.6 times higher odds for lipohypertrophy than rapid plus long-acting analogs $(p=0.014)$. However, the mean injection frequency was lesser for conventional premixed insulins (2.09 vs. 4.01; Table 3). Sub-group analysis showed that lipohypertrophy was $79 \%$ less likely in patients with multiple daily injections $(\geq 4)$ than the twice-daily regimen (unadjusted OR $0.21, p<0.0005)$. Moreover, lipohypertrophy was reduced to half with bolus doses of rapid-acting insulin analogs than the regular insulin $(p=0.003)$ with comparable mean injection frequency (4.01 vs. 3.93, $p=0.229)$. This difference was statistically insignificant for NPH or long-acting analogs basal doses $(p=0.069)$.

\section{DISCUSSION}

Our study demonstrates high prevalence of lipohypertrophy in patients with type 1 diabetes. It was predominantly observed in patients who did not use larger injection area, did not rotate insulin injection sites regularly, administered conventional premixed insulins, and were underweight. Further, needle reuse and frequent injections (basal-bolus regimen) did not increase the likelihood of lipohypertrophy.

In the present study, more than $60 \%$ of the patients developed lipohypertrophy, which is consistent with the recently reported estimate of $69.8 \%$ in Indian T1DM patients (12). Lipohypertrophy is relatively common in T1DM across the world with prevalence ranging from 28.7 to $76.3 \%(2,9-12,24)$. This wide range in prevalence may reflect differences in diagnostic accuracies. Prevalence recorded in the present study is higher than the previous estimates of $41 \%$ from our study center (23). It was not entirely unexpected, as with usual inspection and palpation techniques (21), we also used pinch maneuverer recommended by Gentile et al. (22) that could have improved diagnostic accuracy in the present study.

Correct injection site rotation is the most studied and emphasized approach for the prevention of this undesirable effect of subcutaneous insulin $(2,6,24-26)$. Blanco et al. indicated that only $5 \%$ patients experienced lipohypertrophy who ensured proper rotation (24). Findings of Ji et al. survey shown that risk of exhibiting lipohypertrophy was increased by 8.4 times among rotation non-followers (6). Present study also reinforced the inevitability of correct site rotation in minimizing lipohypertrophy. In comparison to $83.9 \%$ of rotation-refraining patients, only $26.8 \%$ of rotation-complying patients developed lipohypertrophy.

Injection area size is an important determinant in the development of lipohypertrophy. It has been widely discussed that repeated injections in the smaller area could trigger lipohypertrophy $(25,27,28)$. De Coninck et al. observed that $55.2 \%$ of the patients had lipohypertrophy who injected insulin in the area equivalent to credit card size, while it occurred in $42.9 \%$ of those utilizing the area of post card size (27). This association was more pronounced in our study revealing significant proportion of these patients having lipohypertrophy (credit card vs. post card, 88.8 vs. $17.5 \%$ ).

Our and Hauner et al. (2) study underpin the association of low BMI with lipohypertrophy in patients with type 1 diabetes. In ultrasound examination, Perciun et al. demonstrated that remission of muscular and multilayer dystrophies in T1DM children did not happen even after sparing these areas from the insulin injections for 6 months. This finding is of particular interest because 35 of the 45 muscular and multilayer dystrophies were present in the underweight children (29). Conwell et al. also found the negative correlation between BMI Z-score and severity of dermatological changes in T1DM youth using continuous subcutaneous insulin infusion (30). Nevertheless, association of BMI and lipohypertrophy is discussed equivocally in literature. Ji et al. (6) and Saez-de Ibarra et al. (31) found high BMI to be associated with lipohypertrophy. Notably, their patients had $\mathrm{BMI}>18.5 \mathrm{~kg} / \mathrm{m}^{2}$ and were older (range 18-80 and $13-75$ years, respectively) $(6,31)$ than the participants of the Hauner et al. (2) and our study (range 5-48 and 5.0-50.6 years, respectively). Consequently, both sets of studies were driven to measure only 
TABLE 2 | Qualitative independent variables grouped based on lipohypertrophic status and the significance of observed differences.

\begin{tabular}{|c|c|c|c|c|c|}
\hline Variables & & Total number (\%) & $\begin{array}{c}\text { Lipohypertrophy } \\
\text { present number (\%) }\end{array}$ & $\begin{array}{l}\text { Lipohypertrophy } \\
\text { absent number (\%) }\end{array}$ & $\begin{array}{c}\text { Significance } \\
\text { (Pearson Chi square) }\end{array}$ \\
\hline \multicolumn{2}{|l|}{ Patients in study } & $372(100)$ & $231(62.1)$ & $141(37.9)$ & $0.008^{\mathrm{a}}$ \\
\hline & Female & 168 (45.2) & $92(54.8)$ & $76(45.2)$ & \\
\hline Age & $\leq 18$ years & $237(63.7)$ & $153(64.6)$ & $84(35.4)$ & 0.195 \\
\hline & $1-5$ years & $162(43.5)$ & $102(63.0)$ & $60(37.0)$ & \\
\hline & $5-10$ years & $99(26.6)$ & $62(62.6)$ & $37(37.4)$ & \\
\hline & More than 10 years & $62(16.7)$ & 39 (62.9) & $23(37.1)$ & \\
\hline \multirow[t]{2}{*}{ Socio economic status } & Upper & $24(6.5)$ & $13(54.2)$ & $11(45.8)$ & 0.135 \\
\hline & Upper middle & $154(41.4)$ & $87(56.5)$ & $67(43.5)$ & \\
\hline & Overweight (23-27.5) & $41(11.0)$ & $22(53.7)$ & $19(46.3)$ & \\
\hline & Obese (>27.5) & $16(4.3)$ & $3(18.8)$ & $13(81.2)$ & \\
\hline \multirow[t]{3}{*}{ Injection administrator } & Patient & $233(62.6)$ & $144(61.8)$ & $89(38.2)$ & 0.849 \\
\hline & Caregiver & $63(16.9)$ & $41(65.1)$ & $22(34.9)$ & \\
\hline & Patient-Caregiver Dyad & $76(20.4)$ & $46(60.5)$ & 30 (39.5) & \\
\hline \multirow[t]{3}{*}{ Injection device } & Pen & $274(73.7)$ & $155(56.6)$ & $119(43.4)$ & $0.001^{a}$ \\
\hline & Syringe & 75 (20.2) & $58(77.3)$ & $17(22.7)$ & \\
\hline & Pen and Syringe Combined & $23(6.2)$ & 18 (78.3) & $5(21.7)$ & \\
\hline \multirow[t]{2}{*}{ Needle syringe length } & $4 \mathrm{~mm}$ & $221(59.4)$ & $130(58.8)$ & $91(41.2)$ & $0.024^{a}$ \\
\hline & $5 \mathrm{~mm}$ & $18(4.8)$ & $7(38.9)$ & $11(61.1)$ & \\
\hline & Regular plus NPH (3.68) & $28(7.5)$ & $21(75.0)$ & $7(25.0)$ & \\
\hline & Conventional Premixed (2.09) & 47 (12.6) & $41(87.2)$ & $6(12.8)$ & \\
\hline \multirow[t]{3}{*}{ Number of injection sites } & One Site & $203(54.6)$ & $126(62.1)$ & $77(37.9)$ & 0.645 \\
\hline & Two Sites & $106(28.5)$ & $63(59.4)$ & $43(40.6)$ & \\
\hline & Three Sites & $63(16.9)$ & $42(66.7)$ & $21(33.3)$ & \\
\hline \multirow[t]{3}{*}{ Injection area size $(\mathrm{cm} \times \mathrm{cm})$} & Credit card size $(8.56 \times 5.39)$ & $196(52.7)$ & $174(88.8)$ & $22(11.2)$ & $<0.0005^{\mathrm{a}}$ \\
\hline & Playing card size $(8.89$ × 6.35) & $113(30.4)$ & $46(40.7)$ & 67 (59.3) & \\
\hline & Post card size $(14 \times 9)$ & $63(16.9)$ & $11(17.5)$ & $52(82.5)$ & \\
\hline \multirow[t]{2}{*}{ Systematic rotation } & Non-followers & $230(61.8)$ & $193(83.9)$ & $37(16.1)$ & $<0.0005^{\mathrm{a}}$ \\
\hline & Followers & $142(38.2)$ & $38(26.8)$ & $104(73.2)$ & \\
\hline
\end{tabular}

a Statistically significant.

one end of the BMI and reached to opposite conclusions. Hence, BMI may have non-linear relationship with lipohypertrophy and both low and high BMI pose a risk. At least one study comprising wide aged sample (4-78 years) with all ranges of BMI supported this hypothesis (32).
Notably, patients receiving regular insulin plus long-acting analogs had 3.2-fold higher risk of lipohypertrophy than rapid plus long-acting analogs users with same mean injection frequency (4.01 for both). Relatively higher quantum of insulin monomers in rapid-acting analogs attributes to its faster 
TABLE 3 | Unadjusted and adjusted odds ratio of significant variables explaining lipohypertrophy.

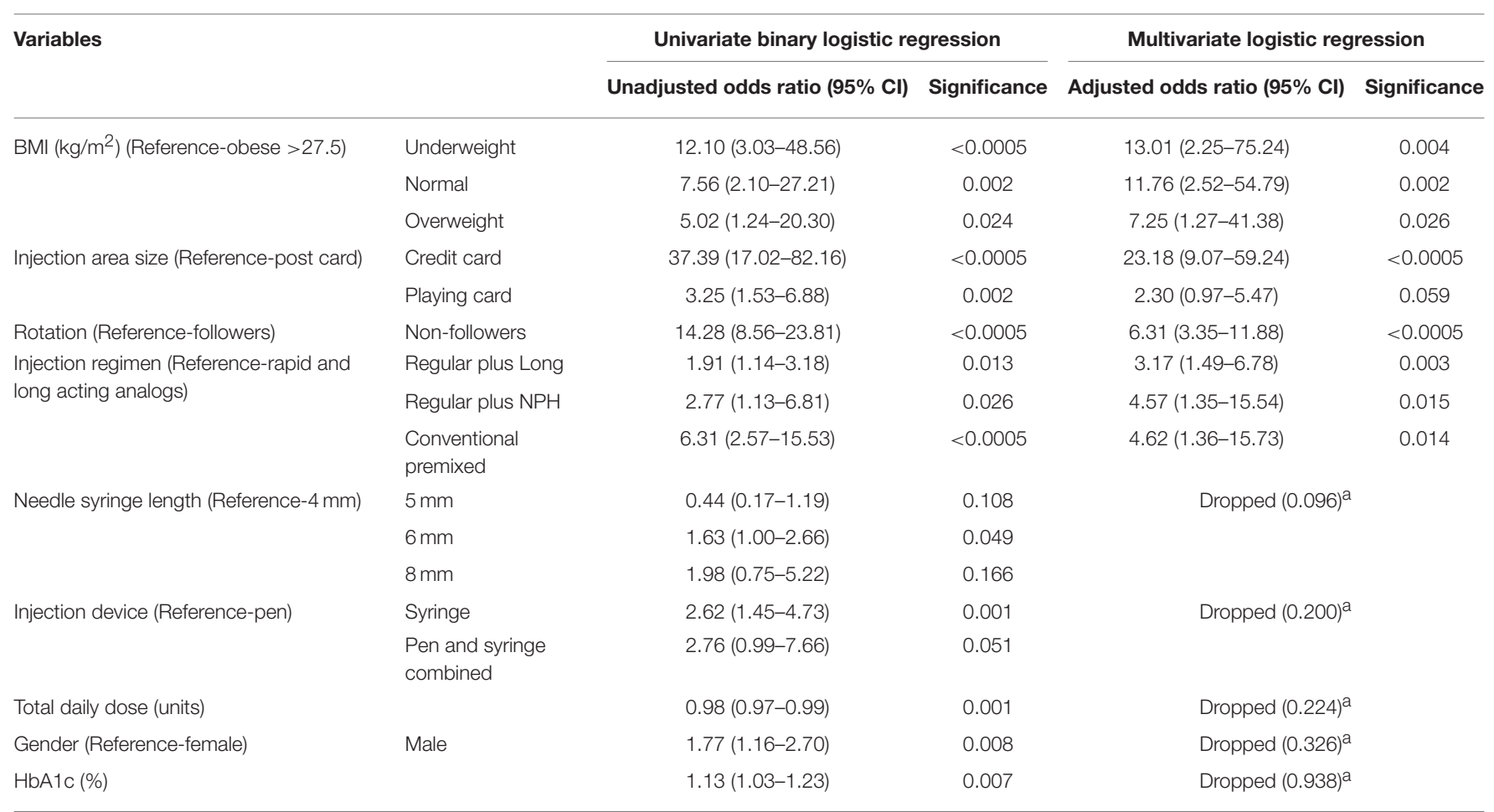

aThese variables became insignificant after adjusting for other variables and was dropped in sequential order to obtain the final model.

absorption from subcutaneous tissue than human insulin. Thus, it can be hypothesized that rapid-acting insulin analogs with their improved pharmacokinetic actions might spare adipocytes from the lipogenic action as compared to conventional insulins. It is further supported by previous reports which suggest that faster absorption of insulin analogs reduces the stay of insulin in adipocytes and thereby provides a break from the local lipogenic action of insulin $(33,34)$. Findings of present study also showed that as compared to multiple daily injections of rapid plus long-acting analogs, risk of lipohypertrophy further augmented to 4.6 times with conventional premixed insulins (twice daily). It was contrary to the opinion that lipohypertrophy is the corollary of repeated tissue trauma caused by frequent injections $(24,25)$. Indeed, distributing total dose in small frequent bouts could minimize the extent of adipocytes' exposure to insulin. Similar trends were observed in study of Gupta et al. (12) for different insulin regimen classes, though inclusion of several insulin subgroups along with small sample size may have limited their ability to detect significant differences.

Our finding of higher $\mathrm{HbAlc}$ levels in patients with lipohypertrophy (mean difference $=0.8 \%$ ) is in line with previous investigations $(6,25,35)$, although the association was not statistically significant in present study. Besides, there are evidences suggestive of more episodes of unexplained hypoglycemia and glycaemic variability in presence of lipohypertrophy $(12,24,25)$. Several pharmacokinetics and pharmacodynamics studies have confirmed that the blunted and varied absorption of insulin from the lipohypertrophic sites could cause glycaemic variability $(3,36,37)$. Lipohypertrophy has also been reportedly associated with diabetic ketoacidosis in adolescents with type 1 diabetes $(25,38,39)$. It has been shown that structured injection technique training could regress lipohypertrophy (7) and improve glycaemic control significantly $(7,40)$.

The clinical benefit received from the current recommendation of using needle just for once to prevent lipohypertrophy, is debatable. Several researches did not find significant difference in needle reuse between the patients with or without lipohypertrophy $(5,11,41)$, consistent with our finding (mean frequency 8.1 vs. 7.2 times). In the beginning of twenty-first century, it was theorized that needle reuse causes deformity, dulling and bending of needle tips; and this added tissue trauma may instigate lipohypertrophy (42). Nevertheless, Kline and Kuhn observed no such damages to tips even after multiple insertions of needles through the rubber stoppers on insulin vials (43). Likewise, Puder et al. (44) and Berger et al. (45) also concluded that injecting into abdominal fat up to 5 and 10 times, respectively, did not lead to needle tip deformity. On the other hand, despite the statistically insignificant $(p=0.067)$ results, the pioneer European survey involving 1,002 patients accredited needle reuse as a contributor to lipohypertrophy (28). Furthermore, many subsequent studies unhesitatingly acknowledged the association of lipohypertrophy with needle reuse, only on the basis of univariate analysis $(12,27,34,46)$. Vardar et al. (26), Blanco et al. (24), Ji et al. (6), and Frid et al. 
(25) did employ the multivariate analysis in their investigations. While Vardar et al. (26) found that lipohypertrophy was associated with needle use more than once; the last three showed its association with lipohypertrophy at the needle reuse frequencies of 5, 7, and 10 times, respectively $(6,24,25)$. Also, a meta-analysis performed by Zabaleta-Del-Olmo et al. demonstrated that in view of heterogeneity among existing scientific evidences, strong recommendation cannot be made regarding the needle reuse and presence of lipohypertrophy (47). Thus, the importance of needle reuse in development of lipohypertrophy has to be viewed with recurring extra expenses and time to comply with. To make a cost effective strategy, there is a high need to set the best cut-off value for the needle reuse frequency.

Therefore, in present study, injection rotation in the larger area had the greatest impact on lipohypertrophy reduction. In addition, patients receiving frequent injections (basal-bolus regimen) and rapid-acting insulin analogs experienced least events. Put together, injection over large area, insulin supply with rapidly absorbed insulins, and dosing in frequent split doses results into better distribution of total daily dose. It minimizes the accumulation of insulin in subcutaneous tissue and spares adipocytes from the lipogenic action of insulin. This notion has partly been discussed $(33,34)$; indeed, Bird et al. reported that one type 1 diabetes patient developed lipohypertrophy at insulin naïve site after $72 \mathrm{~h}$ of long-acting insulin administration but the same did not occur with short-acting insulin (48). Interestingly, needle reuse and frequent injections did not increase the likelihood of lipohypertrophy. In aggregate, lipohypertrophy seems to be a result of lipogenic action of insulin and not of tissue trauma caused by injections. Renold et al. also communicated the very same observation in their experiment (49).

The strengths of present study are large sample size, inclusion of only most commonly prescribed insulin regimens, and use of multivariate statistical analysis. It allowed for robust estimation of the important predictors of lipohypertrophy. To our knowledge, present study provided the first systematic examination of the association of lipohypertrophy with insulin

\section{REFERENCES}

1. Florencia A, Brown A, Cho NH, Dahlquist G, Dodd S, Dunning T, et al. IDF Diabetes Atlas. 6th ed. Brussels: International Diabetes Federation (2013). p. 1-160.

2. Hauner H, Stockamp B, Haastert B. Prevalence of lipohypertrophy in insulintreated diabetic patients and predisposing factors. Exp Clin Endocrinol Diabetes (1996) 104:106-10. doi: 10.1055/s-0029-1211431

3. Famulla S, Hovelmann U, Fischer A, Coester HV, Hermanski L, Kaltheuner M, et al. Insulin injection into lipohypertrophic tissue: blunted and more variable insulin absorption and action and impaired postprandial glucose control. Diabetes Care (2016) 39:1486-92. doi: 10.2337/dc16-0610

4. Deng N, Zhang X, Zhao F, Wang Y, He H. Prevalence of lipohypertrophy in insulin-treated diabetes patients: a systematic review and meta-analysis. $J$ Diabetes Investig. (2018) 9:536-43. doi: 10.1111/jdi.12742

5. Pozzoli MG, Laudato M, Barone M, Crisci F, Pozzuoli B. Errors in insulin treatment management and risk of lipohypertrophy. Acta Diabetol. (2018) 55:67-73. doi: 10.1007/s00592-0171066-y regimens and types of insulin in T1DM patients using a large sample size.

As a limitation, we acknowledge that being single center study, generalization of findings may not be done. In addition, lipodystrophies were not examined through ultrasound imaging. Majority of patients did not perform self-monitoring of blood glucose, which has limited our ability to measure the glycaemic variability and hypoglycaemic episodes.

In conclusion, rotation of injections over the large area and use of rapid plus long-acting insulin analogs in patients with type 1 diabetes are the foremost and modifiable factors for minimizing insulin-related lipohypertrophy. Needle reuse and frequent injections did not contribute to lipohypertrophy.

\section{ETHICS STATEMENT}

The study was approved by the Institutional Ethics Committee (IEC) (Ref no: IEC-04/2016-377) and was performed in accordance with Helsinki Declaration. In case of patients below the age of 18 years, we obtained written assent along with written parental or adult caregiver informed consent. For all the patients above the age of 18 years, a written informed consent was obtained.

\section{AUTHOR CONTRIBUTIONS}

$\mathrm{AjB}, \mathrm{PT}$, and $\mathrm{AiB}$ contributed to the conception and design of the study. AjB acquired and analyzed the data and drafted the manuscript. The work was supervised and monitored by AiB. PT, $\mathrm{AiB}, \mathrm{SG}$, and DD revised the manuscript and provided critically important intellectual inputs. Final version of manuscript was approved by all authors. All the authors agreed to be accountable for the content of the work.

\section{ACKNOWLEDGMENTS}

We are grateful to our patients and their families whose participation made this study possible.

6. Ji L, Sun Z, Li Q, Qin G, Wei Z, Liu J, et al. Lipohypertrophy in China: prevalence, risk factors, insulin consumption and clinical impact. Diabetes Technol Ther. (2017) 19:61-7. doi: 10.1089/dia.2016.0334

7. Campinos C, Le Floch J-P, Petit C, Penfornis A, Winiszewski P, Bordier L, et al. An effective intervention for diabetic lipohypertrophy: results of a randomized, controlled, prospective multicenter study in France. Diabetes Technol Ther. (2017) 19:623-32. doi: 10.1089/dia. 2017.0165

8. McNally PG, Jowett NI, Kurinczuk JJ, Peck RW, Hearnshaw JR. Lipohypertrophy and lipoatrophy complicating treatment with highly purified bovine and porcine insulins. Postgrad Med J. (1988) 64:850-3. doi: 10.1136/pgmj.64.757.850

9. Kordonouri O, Lauterborn R, Deiss D. Lipohypertrophy in young patients with type 1 diabetes. Diabetes Care (2002) 25:634. doi: $10.2337 /$ diacare.25.3.634

10. Al Hayek AA, Robert AA, Braham RB, Al Dawish MA. Frequency of lipohypertrophy and associated risk factors in young patients with type 1 diabetes: a cross-sectional study. Diabetes Ther. (2016) 7:259-67. doi: 10.1007/s13300-016-0161-3 
11. Omar MA, El-Kafoury AA, El-Araby RI. Lipohypertrophy in children and adolescents with type 1 diabetes and the associated factors. BMC Res Notes (2011) 4:290. doi: 10.1186/1756-0500-4-290

12. Gupta SS, Gupta KS, Gathe SS, Bamrah P, Gupta SS. Clinical implications of lipohypertrophy among people with type 1 diabetes in India. Diabetes Technol Ther. (2018) 20:483-91. doi: 10.1089/dia.2018.0074

13. Mortensen H, Hougaard P, Swift P, Hansen L, Holl R, Hoey H, et al. New definition for the partial remission period in children and adolescents with type 1 diabetes. Diabetes Care (2009) 32:1384-90. doi: 10.2337/dc08-1987

14. Real OT, Scale SS, Sharma R. Online Interactive Calculator for Real-Time Update of the Kuppuswamy's Socioeconomic Status Scale. Available online at: www.scaleupdate.weebly.com (Accessed July 18, 2016).

15. Sharma R. Kuppuswamy's socioeconomic status scale-revision for 2011 and formula for real-time updating. Indian J Pediatr. (2012) 79:961-2. doi: 10.1007/s12098-011-0679-3

16. Barba C, Cavalli-Sforza T, Cutter J, Darnton-Hill I, Deurenberg P, Deurenberg-Yap M, et al. Appropriate body-mass index for Asian populations and its implications for policy and intervention strategies. Lancet (2004) 363:157-63. doi: 10.1016/S0140-6736(03)15268-3

17. Khadilkar V, Yadav S, Agrawal K, Tamboli S, Banerjee M, Cherian A, et al. Revised IAP growth charts for height, weight and body mass index for 5-18-year-old Indian children. Indian Pediatr. (2015) 52:47-55. doi: $10.1007 / \mathrm{s} 13312-015-0566-5$

18. ISO/IEC 7810: 2003. Available online at: http://www.iso.org/iso/catalogue_ detail?csnumber=31432 (Accessed September 1, 2015).

19. Post-Card: India Post-Ministry of Communications [Internet]. Available online at: https://www.indiapost.gov.in/MBE/Pages/Content/Post-Card.aspx (Accessed September 1, 2015).

20. Tandon N, Kalra S, Balhara YPS, Baruah MP, Chadha M, Chandalia HB, et al. Forum for injection technique (FIT), India: the Indian recommendations 2.0, for best practice in insulin injection technique, 2015. Indian J Endocrinol Metab. (2015) 19:317-31. doi: 10.4103/2230-8210.152762

21. Seyoum B, Abdulkadir J. Systematic inspection of insulin injection sites for local complications related to incorrect injection technique. Trop Doct. (1996) 26:159-61. doi: 10.1177/004947559602600406

22. Gentile S, Guarino G, Giancaterini A, Guida P, Strollo F. A suitable palpation technique allows to identify skin lipohypertrophic lesions in insulin-treated people with diabetes. Springerplus (2016) 5:563-9. doi: 10.1186/s40064-016-1978-y

23. Sawatkar GU, Kanwar AJ, Dogra S, Bhadada SK, Dayal D. Spectrum of cutaneous manifestations of type 1 diabetes mellitus in 500 south Asian patients. Br J Dermatol. (2014) 171:1402-6. doi: 10.1111/bjd.13077

24. Blanco M, Hernández MT, Strauss KW, Amaya M. Prevalence and risk factors of lipohypertrophy in insulin-injecting patients with diabetes. Diabetes Metab. (2013) 39:445-53. doi: 10.1016/j.diabet.2013.05.006

25. Frid AH, Hirsch LJ, Menchior AR, Morel DR, Strauss KW. Worldwide injection technique questionnaire study: injecting complications and the role of the professional. Mayo Clin Proc. (2016) 91:1224-30. doi: 10.1016/j.mayocp.2016.06.012

26. Vardar B, Kizilci S. Incidence of lipohypertrophy in diabetic patients and a study of influencing factors. Diabetes Res Clin Pract. (2007) 77:231-6. doi: 10.1016/j.diabres.2006.12.023

27. De Coninck C, Frid A, Gaspar R, Hicks D, Hirsch L, Kreugel G, et al. Results and analysis of the 2008-2009 insulin injection technique questionnaire survey. J Diabetes (2010) 2:168-79. doi: 10.1111/j.1753-0407.2010. 00077.x

28. Strauss K, De Gols H, Hannet I, Partanen TM, Frid A. A pan-European epidemiologic study of insulin injection technique in patients with diabetes. Pr Diab Int. (2002) 19:71-6. doi: 10.1002/pdi.314

29. Perciun R, Mihu M. The subcutis ultrasound map of type 1 diabetic children improves the diagnosis of local dystrophies and insulin injection technique. Pediatr Res Int J. (2014) 1-11. doi: 10.5171/2014.402780

30. Conwell louise S, Pope E, Artiles AM, Mohanta A, Daneman A, Daneman D. Dermatological complications of continuous subcutaneous insulin infusion in children and adolescents. J Pediatr. (2008) 152:622-8. doi: 10.1016/j.jpeds.2007.10.006

31. Saez-de Ibarra L, Gallego F. Factors related to lipohypertrophy in insulintreated diabetic patients: role of educational intervention. Pract Diabetes Int. (1998) 15:9-11. doi: 10.1002/pdi.1960150108
32. Hajheydari Z, Kashi Z, Akha O, Akbarzadeh S. Frequency of lipodystrophy induced by recombinant human insulin. Eur Rev Med Pharmacol Sci. (2011) 15:1196-201.

33. Roper NA, Bilous RW. Resolution of lipohypertrophy following change of short-acting insulin to insulin lispro (Humalog). Diabet Med. (1998) 15:1063-4. doi: 10.1002/(SICI)1096-9136(1998120)15:12<1063::AIDDIA706>3.0.CO;2-V

34. Baruah MP, Kalra S, Bose S, Deka J. An audit of insulin usage and insulin injection practices in a large Indian cohort. Indian J Endocrinol Metab. (2017) 21:443-52. doi: 10.4103/ijem.IJEM_548_16

35. Gentile S, Agrusta M, Guarino G, Carbone L, Cavallaro V, Carucci I, et al. Metabolic consequences of incorrect insulin administration techniques in aging subjects with diabetes. Acta Diabetol. (2011) 48:121-5. doi: 10.1007/s00592-009-0172-x

36. Johansson UB, Amsberg S, Hannerz L, Wredling R, Adamson U, Arnqvist HJ, et al. Impaired absorption of insulin aspart from lipohypertrophic injection sites. Diabetes Care (2005) 28:2025-7. doi: 10.2337/diacare.28.8.2025

37. Young RJ, Hannan WJ, Frier BM, Steel JM, Duncan LJ. Diabetic lipohypertrophy delays insulin absorption. Diabetes Care (1984) 7:479-80. doi: 10.2337/diacare.7.5.479

38. Barola A, Tiwari P, Bhansali A. Insulin-mediated lipohypertrophy: an uncommon cause of diabetic ketoacidosis. BMJ Case Rep. (2017) 2017:bcr2017-220387. doi: 10.1136/bcr-2017-220387

39. Al-Hayek AA, Robert AA, Braham RB, Turki AS, Al-Sabaan FS. Frequency and associated risk factors of recurrent diabetic ketoacidosis among Saudi adolescents with type 1 diabetes mellitus. Saudi Med J. (2015) 36:216-20. doi: $10.15537 / \mathrm{smj} .2015 .2 .10560$

40. Misnikova IV, Gubkina VA, Lakeeva TS, Dreval AV. A randomized controlled trial to assess the impact of proper insulin injection technique training on glycemic control. Diabetes Ther. (2017) 8:1309-18. doi: 10.1007/s13300-017-0315-y

41. Cunningham MT, McKenna M. Lipohypertrophy in insulin-treated diabetes: prevalence and associated risk factors. J Diabetes Nurs. (2013) 17:340-3.

42. Partanen T, Rissanen A. Insulin injection practices. Pr Diab Int. (2000) 17:252-4. doi: 10.1002/pdi.91

43. Kline D, Kuhn T. Needle reuse and tip damage. Diabetes Care (2004) 27:617. doi: $10.2337 /$ diacare.27.2.617

44. Puder JJ, Atar M, Muller B, Pavan M, Keller U. Using insulin pen needles up to five times does not affect needle tip shape nor increase pain intensity. Diabetes Res Clin Pract. (2005) 67:119-23. doi: 10.1016/j.diabres.2004. 06.001

45. Berger B, Burian P, Nilsson K, Karlen M, Rylander E. Has RoboCop got diabetes? Diabetes Care (2004) 27:1851. doi: 10.2337/diacare.27.7.1851

46. Ji J, Lou Q. Insulin pen injection technique survey in patients with type 2 diabetes in mainland China in 2010. Curr Med Res Opin. (2014) 30:1087-93. doi: 10.1185/03007995.2014.895711

47. Zabaleta-Del-Olmo E, Vlacho B, Jodar-Fernández L, Urpí-Fernández AM, Lumillo-Gutiérrez I, Agudo-Ugena J, et al. Safety of the reuse of needles for subcutaneous insulin injection: a systematic review and metaanalysis. Int J Nurs Stud. (2016) 60:121-32. doi: 10.1016/j.ijnurstu.2016. 04.010

48. Bird P, Fowler J, Boyle MJ. Early rapid onset lipohypertrophy in a patient with type 1 diabetes mellitus. Aust N Z J Med. (1998) 28:467-8. doi: 10.1111/j.1445-5994.1998.tb02085.x

49. Renold AE, Marble A, Fawcett DW. Action of insulin on deposition of glycogen and storage of fat in adipose tissue. Endocrinology (1950) 46:55-66. doi: 10.1210/endo-46-1-55

Conflict of Interest Statement: The authors declare that the research was conducted in the absence of any commercial or financial relationships that could be construed as a potential conflict of interest.

Copyright (c) 2018 Barola, Tiwari, Bhansali, Grover and Dayal. This is an open-access article distributed under the terms of the Creative Commons Attribution License (CC $B Y)$. The use, distribution or reproduction in other forums is permitted, provided the original author(s) and the copyright owner(s) are credited and that the original publication in this journal is cited, in accordance with accepted academic practice. No use, distribution or reproduction is permitted which does not comply with these terms. 